\title{
Sobre o uso dos dicionários por alunos do Ensino Médio
}

Caroline Chioquetta Lorenset carol.lorenset@gmail.com

Universidade Federal de Santa Catarina, Florianópolis, Brasil

Adja Balbino de Amoroin Barbieri Durão

adjabalbino@gmail.com

Universidade Federal de Santa Catarina, Florianópolis, Brasil

\author{
RESUMO
}

Dicionários - tanto monolíngues quanto bilíngues - e seu uso como recurso auxiliar na sala de aula são pouco pesquisados atualmente no Brasil. Neste artigo, apresentamos aporte teórico sobre Lexicografia e o uso dos dicionários bilíngues na sala de aula do aprendiz de línguas, e mais especificamente de inglês como língua estrangeira. Em nossa pesquisa, buscamos identificar quando e por quais motivos os alunos sentiam necessidade de utilizar dicionários como auxílio em seu aprendizado nas aulas de inglês como língua estrangeira do ensino médio. Conclusões mostram que há ainda uma lacuna quanto ao conhecimento acerca dos diversos usos e funções dos dicionários.
\end{abstract}

PALAVRAS-CHAVE: Uso dos dicionários. Lexicografia. Inglês como língua estrangeira. 


\section{INTRODUÇÃO}

O presente artigo tem como objetivo verificar o uso, aspectos e questões relacionadas aos dicionários bilíngues como ferramenta auxiliar de ensino e aprendizagem de inglês como língua adicional. Neste trabalho, primeiramente, faremos uma breve apresentação de alguns aspectos teóricos da Lexicografia, destacando a importância do uso dos dicionários como material didático na sala de aula de línguas, e mais especificamente, de inglês como língua adicional (doravante ILA). Em seguida, descreveremos o método de pesquisa empregado, assim como os participantes. Passaremos, na sequência, à uma análise descritiva dos instrumentos de pesquisa utilizados com os participantes, que será seguida das considerações finais e das referências utilizadas.

De acordo com Welker (2006), no Brasil, mesmo nos dias atuais, o número de pesquisas sobre o uso do dicionário no geral ainda é muito reduzido. Embora pesquisas sobre uso do dicionário tenham se iniciado ainda no século XIX em outros países, no Brasil as pesquisas já concluídas nesse campo ainda são muito limitadas e referem-se, sobretudo, às situações de compreensão leitora e à retenção de itens lexicais (p. 237). Embora sempre presentes nas prateleiras de livrarias, bibliotecas e salas de aula, além de terem formatos online e em aplicativos, muitos especialistas em ensino de línguas adicionais e alguns professores desaconselham o uso de dicionários. Essa opinião, de acordo com Welker (2008), baseia-se em certas ideias já ultrapassadas a respeito do ensino de línguas adicionais, sem, muitas vezes, ter um fundamento empírico. Esse estudioso menciona que esta opinião pode até ser válida em determinadas situações, mas é equivocada se aplicada à todas as situações de aprendizagem. Nesse sentido, autores afirmam que, principalmente no caso da compreensão leitora, o uso de dicionários tem sido desaconselhado. Entre esses autores, estão Summers (1988), Knight (1994), Coura Sobrinho (2000) e Leffa (2001). Porém, se pesquisas com relação a dicionários já são raras, as pesquisas sobre lexicografia como disciplina de estudo podem ser ainda mais infrequentes.

Lexicografia, de acordo com Fernández (2003), foi considerada, por muito tempo, uma disciplina acientífica, até que na metade do século XX os dicionários começaram a chamar a atenção, sendo considerados não somente fonte de referência, mas também objeto de estudo. Atualmente, contudo, a Lexicografia inclui, além de sua vertente prática, também uma vertente teórica, ocupando, assim, um lugar cada vez mais valorizado no complexo panorama das ciências das linguagens.

Sobre o uso de dicionários no ensino de línguas adicionais (LA), Höfling, Silva e Tosqui $(2006$, p. 70) observa que há uma forte insistência nos cursos de LA de que palavras não devem ser pensadas separadamente e, assim, os dicionários são vistos como reforçadores da tendência do aluno de aprender palavras descontextualizadas na aquisição de uma língua adicional. Os resultados de uma investigação conduzida por Conceição (2004) confirmam que existe essa realidade em que teoria e prática se distanciam no cenário de ensino e aprendizagem de LA nos contextos escolares brasileiros, apontando para uma perpetuação de conceitos de ensino da abordagem tradicional ou gramática e tradução, ainda presente nas salas de aula, através de um ensino focado na leitura e interpretação de textos, uso do dicionário para tradução e listas de 
palavras para memorização. Dessa maneira, consideramos importante ressaltar que utilizamos e incentivamos práticas pedagógicas e didáticas que unam o ensino de língua adicional e a contextualização da cultura junto ao ensino de vocabulário. Indicamos, ainda, que professores incluam em suas práticas o ensino da cultura como algo regular, para que, desta maneira, aprendizes tenham o máximo aporte e incentivo para aprender a língua adicional como um todo, não como habilidades isoladas.

Desde o final do século XIX, vários estudiosos opinaram favoravelmente sobre o uso de dicionários, como Sweet (1899), Thorndike (1928), Mathews (1955), Rivers (1968), entre outros (de acordo com Welker, 2008), usando-os como complemento para as práticas didáticas em salas de aula, e como recurso autônomo para aprendizagem contínua. Um ponto que nos preocupa é o uso dos dicionários em salas de aula sem seu prévio conhecimento. Muitos alunos e professores ainda não conhecem a estrutura de um dicionário, seja ele mono-, biou plurilíngue. De acordo com Höfling, Silva e Tosqui (2004, p. 2), um

\begin{abstract}
dos aspectos mais característicos do dicionário é a forma dupla de apresentação do texto lexicográfico: por um lado há a macroestrutura ou nomenclatura, uma sequência vertical de elementos, chamados de entradas, dispostos geralmente em ordem alfabética; por outro lado a microestrutura, uma sequência horizontal que forma os verbetes, que contêm informações variadas sobre cada entrada. A entrada é cada uma das palavras incluídas na nomenclatura. $O$ verbete é o texto que se segue a uma palavraentrada de um dicionário, cuja principal informação é a definição (no dicionário monolíngue) ou a tradução/equivalente (no dicionário bilíngue)
\end{abstract}

Somando-se temos ainda o lexema, ou seja, a palavra-entrada que inicia o verbete no dicionário, de forma canônica, ou seja, os verbos devem estar no infinitivo e os substantivos no masculino singular. O lexema compõe a entrada do verbete, fazendo parte de sua macroestrutura. Por outro lado, na microestrutura devem ser contemplados não apenas os elementos da língua, mas também os do discurso, em qualquer de suas flexões possíveis, e/ou também expressões idiomáticas. Miranda (2007) afirma que o conceito de macroestrutura depende do estudioso e de suas vertentes, mas o autor cria alguns parâmetros para guiar a definição da macroestrutura do dicionário de língua:

1) definição macroestrutural e usuário;

2) 2) tipo de dicionário e número de entradas;

3) 3) constituição da macroestrutura no dicionário de língua; e

4) 4) critérios de lematização: disposição alfabético-progressiva.

De acordo com Welker (2004), a macroestrutura consta do arranjo das entradas, tamanho da nomenclatura, e fontes e corpora; enquanto que a microestrutura consiste em cabeça do verbete (variantes ortográficas, pronúncia, marcas de uso e etimologia), definição, diferenciação e ordenação das acepções, marcas de uso (independentes), informações sintáticas, colocações, exemplos, fraseologismos idiomáticos, e remissões e informações paradigmáticas. 
Conhecendo bem o dicionário, seu potencial e seus objetivos, cabe aos professores formular atividades que ajudem os alunos a entrarem nesse novo mundo que é o texto lexicográfico. Como sugerem Höfling, Silva e Tosqui (2004, p. 4), é preciso conviver com os dicionários, folheá-los e utilizá-los. Além de coadjuvante no ensino, usado nas tarefas dentro e fora da sala de aula, o dicionário pode ter um papel principal, tornando-se o próprio objeto de atividades que proporcionem o desenvolvimento lexical dos aprendizes, como vamos demonstrar no próximo tópico. É importante que o professor leia partes do dicionário com seus alunos, destacando para eles para que público-alvo este foi pensando, qual é seu objetivo principal e sua apresentação como um todo, incluindo a leitura das informações extras, como moedas diversas, mapas, lista de verbos irregulares, entre outras.

Yaman (2015) destaca o ponto de vista de que não é certo ignorar o papel de dicionários no aprendizado de línguas em todos seus níveis, do iniciante ao avançado. Mesmo falantes nativos podem precisar consultar dicionários de tempos em tempos, uma vez que é impossível saber o significado de cada item lexical de uma língua. A aprendizagem de vocabulário é central para a aquisição de linguagem, não importando se este idioma é o primeiro, segundo ou terceiro. Por conseguinte, pode-se dizer que o uso de dicionários é um recurso em termos de vocabulário em todas as fases da aprendizagem de línguas para todos os tipos de alunos. (YAMAN, 2015, p. 1479).

Höfling, Silva e Tosqui (2006, p. 55) explicam que existem seis tipos de atividades que têm como objetivo a familiarização do aprendiz com o uso do dicionário, sendo elas:

1) atividades para um primeiro contato do aprendiz com o dicionário, como a introdução à terminologia básica e partes importantes de um dicionário;

2) atividades com palavras-chave, ou seja, exercícios que levem em conta as diferentes partes do discurso, formação de palavras, símbolos fonéticos;

3) atividades com o significado, a definição apresentada no dicionário, a relação e a associação entre palavras;

4) atividades que promovem o desenvolvimento do vocabulário do aprendiz, como por exemplo exercícios referentes a campos lexicais, expressões idiomáticas, e colocações;

5) atividades de compreensão de textos autênticos na língua adicional, com o dicionário sendo utilizado como uma das estratégias de leitura aplicadas pelo aprendiz; e, finalmente,

6) atividades que focalizam uma comparação entre vantagens e desvantagens de se optar por dicionários monolíngues ou bilíngues em situações diferentes de aprendizagem.

Estas atividades são nada mais que sugestões sobre como auxiliar o aprendiz a adquirir inglês como LA, considerando que, com o apoio do dicionário, alunos podem aprender níveis linguísticos (semântica, sintaxe, morfologia, fonética, pragmática), desenvolvendo leitura e interpretação de texto; desenvolvimento de vocabulário; gramática; pronúncia; o uso de língua; entre outros. 
Atualmente, com a ubiquidade da tecnologia digital e o constante desenvolvimento de tecnologias educacionais, dicionários eletrônicos estão ganhando cada vez mais espaço na vida escolar. Assim sendo, professores e educadores podem aproveitar esse recurso em suas práticas didáticas usuais. De acordo Atkins (1996), as vantagens dos dicionários online ou em aplicativos são inúmeras, dentre elas: a) funciona com o uso do hipertexto, que eliminará restrições de texto lineares, abrindo o caminho para novos tipos de informação e, portanto, oferece novas maneiras de apresentação; b) permite amplo espaço para evitar a sobrecarga aos consulentes; c) aceita menos ou nenhuma distorção das descrições da língua-fonte pela língua-alvo; d) admite uma compilação flexível e livre da ordem alfabética; e) permite maneiras alternativas de apresentar informação, como por exemplo em gráficos; f) garante acesso rápido a grandes quantidades de evidência lexicográfica em bancos de dados; e g) aceita customização em grande escala aos consulentes; entre outras. Porém, apesar de todas estas vantagens e conquistas adquiridas com o advento da tecnologia digital, ainda há o problema de confiabilidade.

Para Arroyo (2003), o grau de fiabilidade dos principais dicionários digitais pode ser uma vantagem ou uma desvantagem. É extremamente necessário identificar quem são os autores, a instituição ou editora que patrocinam cada dicionário. Uma desvantagem, de acordo com essa autora, é a estabilidade. Tendo em vista que conteúdos digitais não são permanentes, a conservação e estabilidade do material editado deve evidenciar quando e por quem são feitas as atualizações, objetivando a clareza de informações disponíveis aos usuários (ARROYO, 2003). Apesar de ainda haver necessidade de professores auxiliarem no uso de dicionários físicos impressos, também há necessidade da instrução do uso do dicionário digital, a fim de que alunos aprendam a utilizar dicionários confiáveis e verossímeis online ou em aplicativos. Mesmo em dicionários digitais, de acordo com Atkins (1996), mudança e inovação não são costumeiros em função do alto custo, fazendo com que permaneçam os mesmos em sua essência, apesar da relevância das pesquisas linguísticas realizadas especialmente na área de semântica lexical. Em relação ao passado, existe uma longa tradição sobre a produção e criação de dicionários, e uma rica herança de pesquisas para serem analisadas. Porém, com o corpus eletrônico atualmente disponível através da tecnologia digital, vive-se uma riqueza de evidência lexical que antes nunca fora sonhada, incluindo também a liberação da página impressa e da ordem alfabética como único recurso do consulente.

A falta de informações sobre qual dicionário comprar ou como e quando utilizá-lo pode levar a um uso não produtivo e, consequentemente, à uma frustração e desestímulo por parte do usuário. Por conseguinte, acreditamos ser papel do professor indicar a seu aluno qual dicionário adquirir e como explorar suas qualidades, levando em conta o perfil e as necessidades deste aluno em cada caso. Dicionários devem ser utilizados não somente durante as aulas de inglês como LA, mas também como ferramenta de aprendizado autônomo fora da escola. Porém, para que este material seja bem aproveitado, é imprescindível que o professor saiba desenvolver diferentes atividades, explorando as várias possibilidades de uso do dicionário, como sugerido anteriormente. 


\section{MÉTODO}

O método de pesquisa consta da aplicação, análise e interpretação dos questionários aplicados aos alunos do ensino médio integrado, conforme descrito nas subseções abaixo.

\section{1) PARTICIPANTE}

Os participantes desta pesquisa são alunos da unidade curricular de inglês na terceira fase de seus cursos técnicos integrados, do Instituto Federal de Santa Catarina (IFSC), campus Florianópolis. A terceira fase do curso seria como o primeiro semestre do segundo ano do ensino médio regular, porém, no IFSC, no terceiro, quarto e quinto semestres, os alunos aprendem inglês como língua adicional. A fim de otimizar o tempo em sala de aula em termos de didática, uma prova de nivelamento é aplicada ao início da terceira fase, a fim de unir alunos nos seus níveis aproximados de conhecimento do idioma: básico, intermediário e avançado. Desta maneira, as turmas ficam diversificadas com alunos de vários cursos técnicos do campus, como química, saneamento e eletrotécnica, porém, com os alunos sentindo-se mais à vontade para produzir e tomar riscos com seus colegas de nível de conhecimento similar. A terceira fase e o nível básico foram escolhidos por este ser o primeiro momento em contato com ILA na escola. No total, foram trinte e oito (38) participantes adolescentes.

\section{2) QUESTIONÁRIO}

Os questionários (Anexo) aplicados aos participantes foram elaborados a fim de sanar dúvidas das pesquisadoras em relação ao uso dos dicionários por parte dos alunos, seja em casa, na sala de aula ou em grupos de estudo. Também foi questionado em que momento os alunos sentiam necessidade de pesquisar em dicionário, de que forma seu uso acontecia e em que momento. Tanto a análise quanto a interpretação dos questionários foram transformadas em gráficos, como poderá ser visto na próxima seção, a fim de clarificar e ilustrar os resultados.

\section{ANÁLISE}

Após análise e interpretação dos questionários, os dados foram transformados em gráficos para melhor visualização do leitor. O questionário (Anexo) foi aplicado para os alunos das terceiras fases do ensino médio técnico do IFSC campus Florianópolis, como explicitado na seção anterior. Antes da entrega dos questionários, foi explicado aos alunos o propósito da pesquisa e as dúvidas dos alunos foram sanadas.

Como resposta para a primeira pergunta que investigava se os alunos já haviam estudado inglês antes da terceira fase no IFSC, trinta e um alunos, ou seja, a grande maioria, afirmou já ter estudado esta língua adicional anteriormente. Estes dados podem ser verificados no gráfico 1, abaixo. Muito provavelmente, estes alunos haviam estudado inglês como parte do currículo escolar integrante 
do ensino fundamental em suas vidas escolares anteriores ao ingresso no IFSC, onde os respondentes atualmente estudam no ensino médio. Quanto aos alunos que afirmam nunca ter estudado inglês antes, as pesquisadoras pensam em duas hipóteses: a) os alunos não entenderam a pergunta; ou b) os alunos estudaram outra língua estrangeira no ensino fundamental, tendo em vista sua obrigatoriedade desde a Lei de Diretrizes e Bases de $1996^{1}$.

Gráfico 1: Já estudou inglês antes da 3a fase no IFSC?

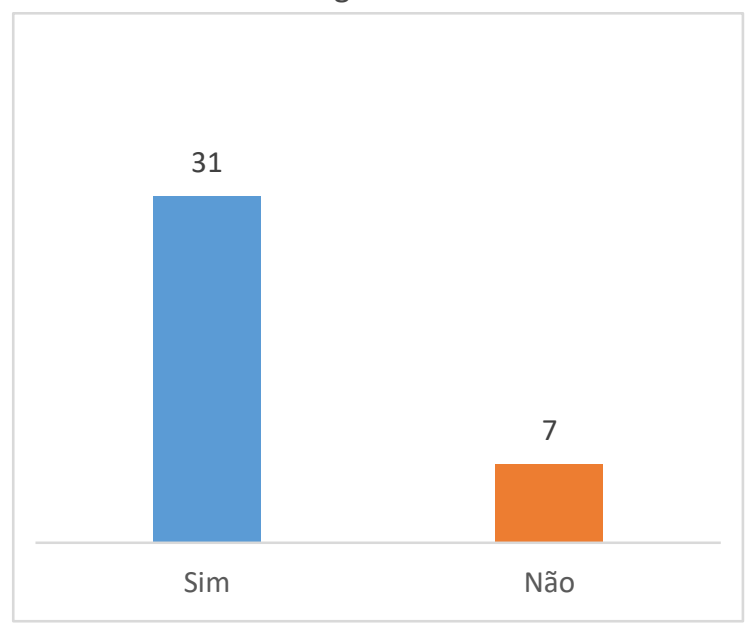

Com relação à segunda pergunta, que pode ser visualizada no gráfico 2 , vinte e oito alunos responderam que possuem dicionário em casa, não importando se estes eram mono- ou bilíngues. As pesquisadoras tinham a intenção, com esta pergunta, de saber a importância e a valorização dada pelos alunos e suas famílias quanto a aquisição do dicionário para uso domiciliar deste recurso de ensino. Um aluno participante não respondeu esta pergunta no questionário. Vemos, portanto, que grande parte dos alunos possuem dicionários em suas casas, mesmo que estes sejam herdados de irmãos mais velhos ou de outros familiares.

Gráfico 2: Você possui dicionário em casa?

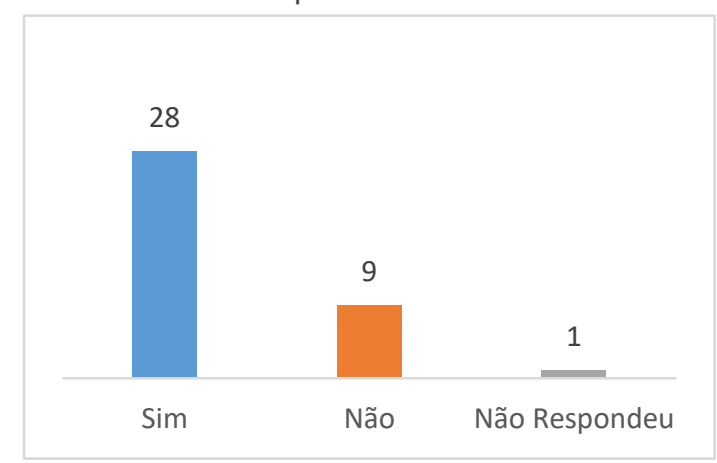

$\mathrm{Na}$ terceira pergunta, podemos verificar que vinte e um alunos afirmaram não fazer uso dos dicionários disponíveis na biblioteca do campus IFSC Florianópolis, mesmo sabendo que a escola os fornece para empréstimo e uso durante as aulas. Um aluno participante não respondeu esta pergunta no questionário. 0 gráfico 3 , referente a esta pergunta, encontra-se abaixo. 
Gráfico 3: A biblioteca da sua escola oferece dicionários bilíngues e monolíngues. Você já os utilizou?

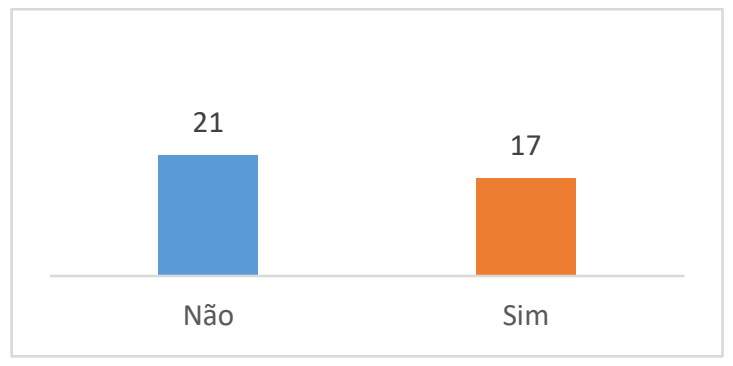

Em relação à quarta pergunta, conferimos que o uso dos dicionários por meios digitais tecnológicos é alto, pois a maioria, ou seja, vinte e oito alunos, confirmaram o uso do dicionário por meio online ou de aplicativo. Este resultado nos informa que alunos estão integrando o meio tecnológico digital ao seu processo de aprendizado. No gráfico abaixo temos a ilustração através de gráficos das respostas dos alunos à pergunta do questionário.

Gráfico 4: Você utiliza aplicativos de dicionários ou dicionários on-line?

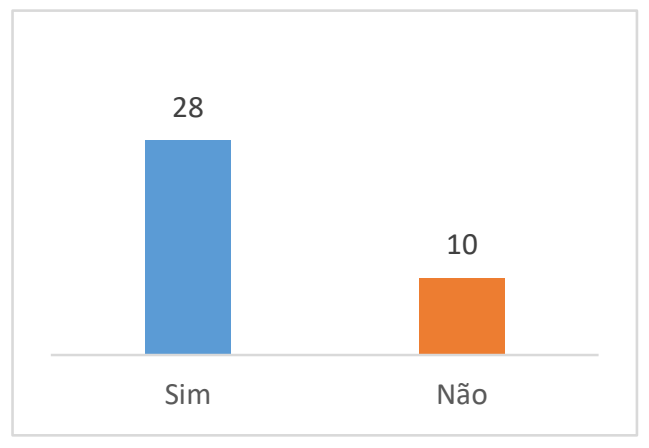

Na quinta pergunta do questionário, "Você utiliza o dicionário como meio para auxiliar sua aprendizagem de inglês como língua adicional?", podemos averiguar no gráfico 5 abaixo que vinte e nove alunos responderam utilizar o dicionário para auxiliar a aprendizagem de inglês como língua adicional. Este é um bom indício, pois mostra que os alunos buscam aprender de forma autônoma a língua adicional em questão.

Gráfico 5: Você utiliza o dicionário como meio para auxiliar sua aprendizagem de inglês como língua adicional?

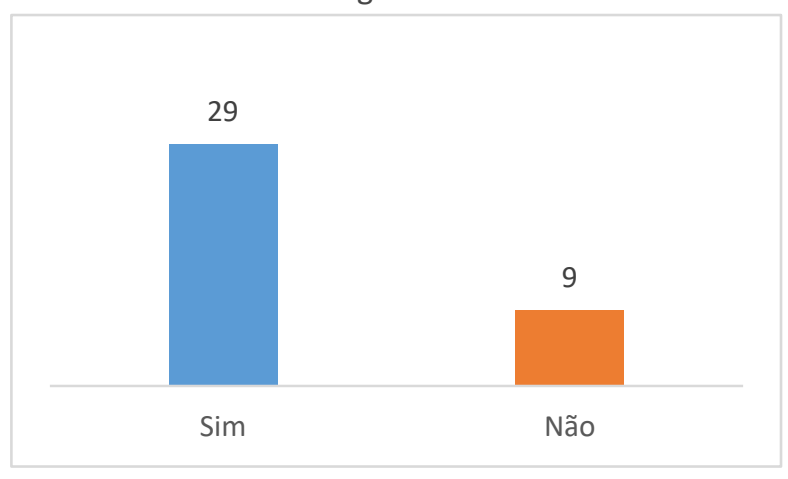


Na sexta pergunta, mais de uma alternativa era aceita como resposta. Esta pergunta, como pode ser constatada no gráfico 6 , investiga o tipo de dicionário mais utilizado pelos alunos respondentes. Como pode ser averiguado abaixo, vinte e oito alunos utilizam dicionários bilíngues para auxiliar no seu aprendizado, enquanto que vinte e três alunos também fazem uso dos dicionários online. Dez alunos afirmam utilizar aplicativos de dicionários. Quatro alunos afirmaram utilizar dicionário monolíngues. A minoria, dois alunos, afirmou fazer uso de outros tipos de dicionários, como o semibilíngue ou plurilíngue, por exemplo. Um aluno afirmou utilizar dicionário nenhum. Como nas questões anteriores sempre apareciam ao menos 9 alunos que não utilizavam dicionários, as pesquisadoras esperavam que este número fosse maior. Constata-se, portanto, que os alunos, mesmo os que não possuem dicionários em casa, utilizam-nos como recurso digital ou físico para aprendizagem.

Gráfico 6: Que tipo de dicionário você usa para auxiliá-lo na aprendizagem de inglês como língua adicional? Assinale quantas alternativas forem necessárias.

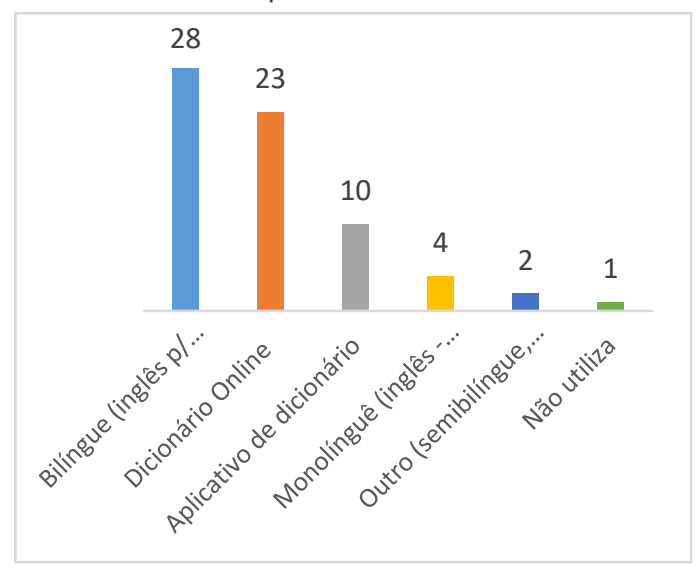

Muito similar à pergunta seis, a pergunta sete do questionário também podia ter quantas alternativas assinaladas quanto fossem necessárias. Na resposta, trinta e cinco alunos afirmaram utilizar o dicionário para procurar o significado de uma palavra, enquanto que vinte e seis alunos afirmaram utilizá-lo para procurar a ortografia correta de uma palavra. Logo em seguida, em terceiro lugar, dezessete alunos asseguraram que usam dicionário para checagem de pronúncia, e outros nove alunos procuram por sinônimos ou antônimos de uma palavra. Sete alunos assinalaram que usam dicionários para saber mais sobre uma palavra (se é verbo, substantivo, adjetivo ou advérbio, por exemplo), para pesquisar na lista de verbos irregulares de inglês, e também para consultar acentuação gráfica. Outros três alunos consultam a separação silábica. Dois alunos colocaram outros motivos para usar dicionário, sendo eles a procura por palavras ou "gírias derivadas de jogos", e outro aluno afirmou não fazer uso nenhum do dicionário. Por fim, um aluno afirmou que utiliza o dicionário para saber mais sobre as informações extras, como moedas e mapas, presentes nos dicionários. 
Gráfico 7: Para quais motivos listados abaixo você utiliza o dicionário? Assinale quantas alternativas forem necessárias

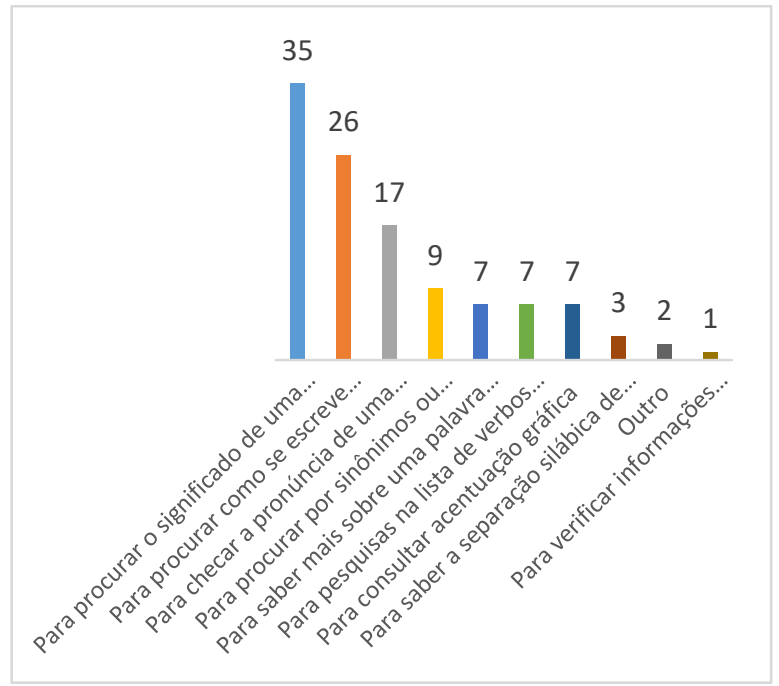

Finalmente, na última questão, de número oito, vinte e dois alunos afirmaram nunca terem recebido nenhuma instrução ou explicação sobre o uso de dicionários em sua vida escolar. Dezesseis alunos, entretanto, afirmaram já terem recebido instruções de professores de língua portuguesa ou língua adicional anteriormente. Muitos dos alunos que não receberam instrução de como utilizar dicionários para seu uso mais completo, informaram, porém, ter recebido explicação em casa, vindo dos pais.

Gráfico 8: Em sua vida escolar, alguma vez você recebeu instrução para utilizar dicionários? Se sim, por favor justifique sua resposta.

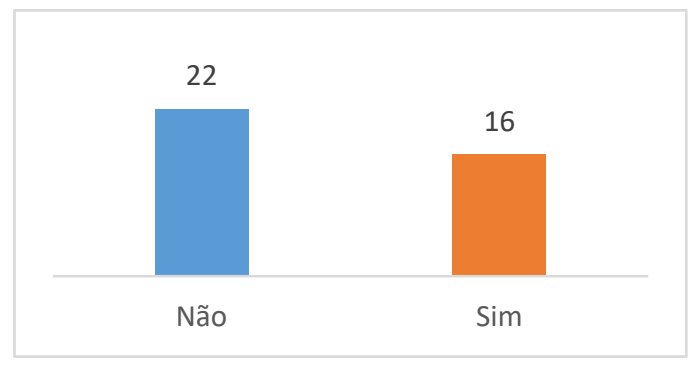

Como pudemos averiguar nesta seção, o uso dos dicionários faz parte da rotina escolar da maioria dos alunos das terceiras fases do ensino médio técnico integrado do campus Florianópolis do IFSC, principalmente os mono- e os bilíngues. A grande maioria dos alunos afirmou utilizar dicionário impresso, online ou em aplicativos, principalmente para checar significados de palavras, e para verificar sua ortografia e pronúncia. Apesar de muitos não terem recebido instruções de como utilizar os dicionários na escola, a fim de explorar toda a capacidade de conhecimento contida neles, estes alunos ainda fazem uso dos dicionários como recurso auxiliar de seu aprendizado. O grande número de alunos que fazem uso de dicionários digitais, sejam eles online ou em aplicativos, mostra sua preocupação em usá-los de forma a acrescentar e aumentar seu desenvolvimento de aprendizado. Para tanto, sugerimos que professores devam 
aproveitar este indício para utilizar dicionários e incluí-lo em suas práticas didático-pedagógicas. A seguir, sugerimos algumas abordagens de inserção do dicionário na sala de aula e no desenvolvimento do aprendizado de línguas adicionais.

Por fim, em função de os alunos participantes nesta pesquisa serem aprendizes de nível básico de inglês como língua adicional, trazemos uma sugestão de atividade mencionada em Höfling, Silva e Tosqui (2004). A atividade, dirigida a aprendizes de nível básico a intermediário tem duração de trinta minutos, e diz respeito à polissemia das palavras, cuja noção deve ser assimilada pelos aprendizes no início do aprendizado de uma LA. Uma palavra pode ter vários significados que só se diferenciam de acordo com o contexto em que ela se insere. $O$ dicionário fornece palavras descontextualizadas que servem de base para o aprendiz inferir seu significado atualizado dentro da estrutura de uma frase e do contexto de comunicação. Inicialmente, o aprendiz deve procurar no dicionário bilíngue os significados das palavras sublinhadas em um texto. Em seguida, o professor pede ao aprendiz que complete algumas frases com as palavras que acabou de procurar no dicionário. Entretanto, as palavras só caberão nessas frases com um outro significado. $\mathrm{O}$ aprendiz, por sua vez, pode procurar tal palavra novamente no dicionário bilíngue, criando no aprendiz uma conscientização a respeito de palavras polissêmicas (HÖFLING, SILVA E TOSQUI, 2004 , p. 6). Desta maneira, o aluno vai aprender a se servir das diferentes obras, além de exercitar a habilidade de procurar por diferentes classes gramaticais da mesma palavra no verbete do dicionário, como por exemplo, book (substantivo e verbo) ou sweet (adjetivo e substantivo).

\section{CONSIDERAÇÕES FINAIS}

Neste artigo, apresentamos breve aporte teórico relacionado aos estudos acerca dos dicionários e da Lexicografia. Verificamos que ainda há muito espaço para pesquisa nestas áreas no Brasil. Através de um questionário aplicado a trinte e oito alunos de nível básico, iniciantes em seus estudos de inglês como língua adicional, verificamos que existe ainda uma lacuna no que se refere à falta de conhecimento acerca dos dicionários. O que falta, tanto em muitos professores quanto em alunos, é conhecer os dicionários, aprender a usá-los corretamente, saber buscar cada tipo de informação e, acima de tudo, saber quando usar o dicionário.

Apesar de dicionários poderem ser acessados e procurados com a ubiquidade da tecnologia digital, percebemos pouco uso que vá além do significado, ortografia e pronúncia das palavras. Estes três usos foram os mais assinalados pelos alunos no questionário, demonstrando a falta de conhecimento sobre a obra completa que um dicionário é. Além disso, claro, não podemos deixar de comentar sobre a confiabilidade sobre dos dicionários e seus editores. Por isso, recomendamos a leitura séria do dicionário como um todo, seus objetivos e público alvo, a fim de utilizá-lo da melhor forma. Dicionários são uma ótima fonte de informações, podendo muitas vezes ser complementar ao material didático utilizado por muitos professores, empregados tanto em atividades em grupo ou individualmente no ensino de inglês como língua adicional. 
Concluímos, portanto, que dicionários devem ser utilizados como meio complementar e recurso para o desenvolvimento do ensino e aprendizado de línguas adicionais. Dicionários são ferramentas poderosas que devem ser exploradas de forma a contribuir, melhorar e motivar o aprendizado no geral, não somente de línguas adicionais. Defendemos, ainda, frequentes explicações e capacitações sobre dicionários nas escolas, tanto para professores quanto para alunos e toda a comunidade escolar. 


\title{
On the use of dictionaries by High School students
}

\begin{abstract}
Dictionaries - both monolingual and bilingual - and their use as a resource in the classroom are little researched currently in Brazil. In this article, we present a theoretical contribution on Lexicography and the use of bilingual dictionaries in the learner's classroom, and more specifically of English as a foreign language. In our research, we intend to identify when and by which means the students felt the need to use these materials as an aid in learning English as a foreign language in high school. Conclusions show that there is a gap regarding knowledge about the various uses and functions of dictionaries.
\end{abstract}

KEYWORDS: Use of dictionaries. Lexicography. English as Foreign Language. 


\section{NOTAS}

${ }^{1}$ Como pode ser verificado em: <http://portal.mec.gov.br/seesp/arquivos/pdf/lei9394_ldbn1.pdfs. Acessoem: fev. 2018.

\section{REFERÊNCIAS}

ARROYO, C. G. El estado actual de la lexicografía: los nuevos diccionarios". Medina Guerra, Antonia M. (ed.) Lexicografía Española. Barcelona: Ariel, 307328. 2003.

ATKINS, B. T. S. Bilingual dictionaries: Past, present and future. Gellerstam, M., Jarborg, J., Malmgren,S. G., Rogström, L. \& Papmehl, C. R. (Eds.), Euralex'96 Proceedings. P. 515-546. Göteborg: Göteborg University, 1996.

CONCEIÇÃO, M. P. Experiências de aprendizagem: reflexões sobre o ensino de língua estrangeira no contexto escolar brasileiro. Revista Brasileira de Linguística Aplicada, volume 6, número 2, p. 185 - 206, 2006.

FERNÁNDEZ, D. A. La lexicografía como disciplina linguística. Lexicografía española, Antonia María e Medina Guerra (ed.), p. 31 - 52, 2003.

HÖFLING, C., SILVA, M.C.P, TOSQUI, P. O Dicionário como Material Didático na Aula de Língua Estrangeira. Intercâmbio, volume XIII, São Paulo: LAEL-PUC/SP p. $1-7,2004$.

. Técnicas de utilização de dicionário como material didático na aula de LE para fins específicos. Revista Brasileira de Linguística Aplicada, volume 6, número 1, 2006.

MIRANDA, F. B. O que é macroestrutura no dicionário de língua?. Aparecida Negri Isquerdo; leda Maria Alves. (Org.). As ciências do Léxico: Lexicologia, lexicografia e terminologia. São Paulo: Humanitas, volume III, p. 261-272, 2007.

YAMAN, I. Exploring the Dictionary Preferences of Prospective English Language Teachers. International Journal of Languages' Education and Teaching, p. 1478 1490, 2015.

WELKER, H. A. Pesquisando o uso de dicionários. Linguagem \& Ensino, volume 9, número 2, p. 223 - 243, jul. /dez. 2006. 
. O dicionário monolíngue geral seletivo: componentes e organização.

Dicionários: Uma pequena introdução à lexicografia. Brasília: Thesaurus, p. 77 182, 2004.

\author{
ANEXOS \\ Este questionário faz parte de uma pesquisa e tem como objetivo o \\ conhecimento da pesquisadora sobre o seu uso do dicionário bilíngue no \\ processo de aprendizagem de inglês como língua adicional. Não vale nota nem \\ pontuação na média final. Como você não precisa se identificar, espera-se sua \\ resposta mais sincera e condizente à realidade. \\ 1. Já estudou inglês antes da $3^{\text {a }}$ fase no IFSC? \\ ( ) Sim ( ) Não \\ 2. Você possui dicionário em casa? \\ ( ) Sim ( ) Não \\ 3. A biblioteca da sua escola oferece dicionários bilíngues e monolíngues. \\ Você já os utilizou? \\ ( ) Sim ( ) Não \\ 4. Você utiliza aplicativos de dicionários ou dicionários on-line? \\ ( ) Sim ( ) Não \\ 5. Você utiliza o dicionário como meio para auxiliar sua aprendizagem de \\ inglês como língua adicional? \\ ( ) Sim. Justifique sua resposta: \\ ( ) Não. Justifique sua resposta:
}

6. Que tipo de dicionário você usa para auxiliá-lo na aprendizagem de inglês como língua adicional? Assinale quantas alternativas forem necessárias:

( ) Monolíngue (inglês - inglês)

( ) Bilíngue (inglês/português e português/inglês)

( ) Outro (semibilíngue, plurilíngue, de sinônimos e antônimos, temáticos, de abreviaturas, etimológico)

( ) Aplicativo de dicionário

( ) Dicionário online

7. Para quais motivos listados abaixo você utiliza o dicionário? Assinale quantas alternativas forem necessárias:

( ) Para procurar o significado de uma palavra

( ) Para procurar como se escreve corretamente uma palavra

( ) Para saber mais sobre uma palavra (se é verbo, substantivo, adjetivo, etc.)

( ) Para procurar por sinônimos ou antônimos de uma palavra

( ) Para saber a separação silábica de uma palavra

( ) Para checar a pronúncia de uma palavra

( ) Para verificar informações adicionais, como medidas internacionais, moedas, mapas, etc.

( ) Para pesquisas na lista de verbos irregulares de inglês

( ) Para consultar acentuação gráfica

( ) Outro:

8. Em sua vida escolar, alguma vez você recebeu instrução para utilizar dicionários? Se sim, por favor justifique sua resposta. 


\section{( ) Sim. Justifique sua resposta:}

( ) Não.

Recebido: 08 ago. 2017

Aprovado: 07 set. 2017

DOI: 10.3895/rl.v19n26.6907

Como citar: LORENSET, Caroline Chioquetta; DURÃO, Adja Balbino de Amorim Barbieri. Sobre o uso dos dicionários por alunos do ensino médio. R. Letras, Curitiba, v. 19, n. 26, p. 120-135, set. 2017. Disponível em: <https://periodicos.utfpr.edu.br/rl>. Acesso em: XXX.

Direito autoral: Este artigo está licenciado sob os termos da Licença Creative Commons-Atribuição 4.0 Internacional.

\section{(c) (1)}

